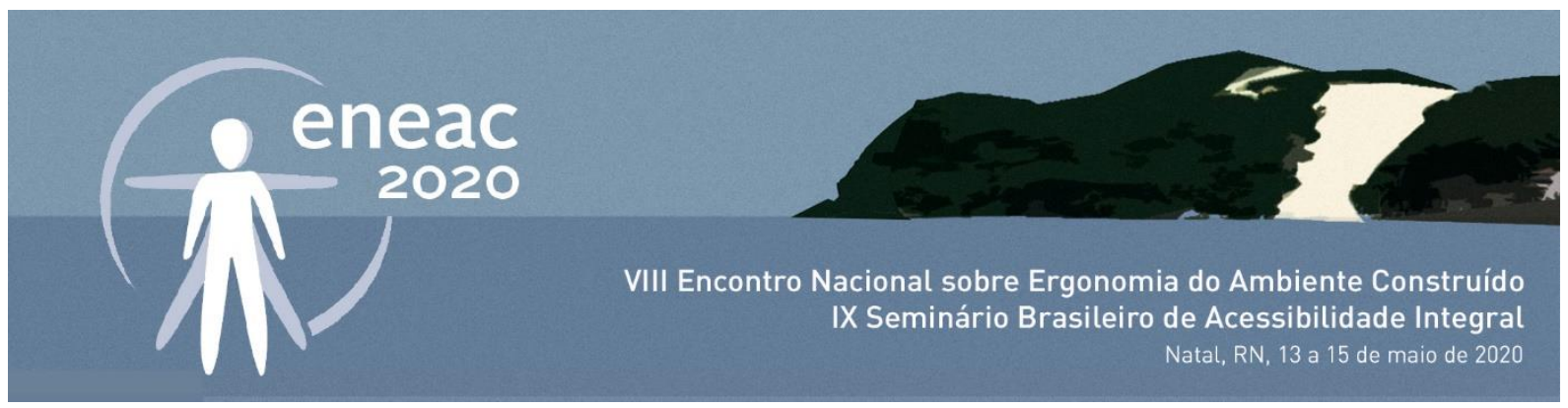

\title{
Sobre ir e vir: os obstáculos de uma rota acessível - Biblioteca Central da UFPE, Recife-PE
}

\author{
On coming and going: the obstacles of an accessible route - \\ Bibliotheca Central of UFPE, Recife-PE
}

\begin{abstract}
KAROLINE LIMA NASCIMENTO
Arquiteta e Urbanista, Discente da pós-graduação em Design e Inovação em Interiores, UNIESP, karoline.tg.ufpe@gmail.com

FERNANDA ÂNGELO DINIZ Designer de Interiores, Discente da pós-graduação em Design e Inovação em Interiores, UNIESP, adinizfernanda@hotmail.com

LARISSA NASCIMENTO DOS SANTOS Doutoranda em Design, Coordenadora do curso de Design de Interiores, UNIESP, larissansns@gmail.com

JÚLIO CÉSAR FÉLIX DE ALENCAR FERNANDES Doutorando em Design, Professor do curso de Design de Interiores, UNIESP, julio.interiores85@gmail.com
\end{abstract}

\begin{abstract}
RESUMO
No Brasil, a acessibilidade tem sido um tema quase sempre percebido apenas sob o ponto de vista legal, porém mesmo que o país possua um conjunto de leis que em teoria garantam tratamento igualitário a todos, participe de eventos internacionais sobre o tema e assine acordos, este não desenvolveu ainda a cultura da inclusão social de pessoas com deficiência e restrição de mobilidade. $\mathrm{O}$ artigo tem como objetivo apresentar as condições atuais de acessibilidade de uma rota no interior da Universidade Federal de Pernambuco (UFPE), localizada em Recife - PE, mais precisamente no edifício da Biblioteca Central - térreo, bem como identificar as dificuldades no processo de mobilidade dos funcionários e alunos no interior da mesma. Para tal, foi utilizada como metodologia uma atividade desenvolvida durante um módulo da pós-graduação em "Design e Inovação em Interiores" como requisito para conclusão do mesmo, sendo utilizada como técnica a observação assistemática acompanhada do registro fotográfico. A rota mostrou que a edificação apresenta diversas falhas no que diz respeito à garantia da autonomia das pessoas com deficiência. Entretanto, tais inconformidades são passíveis de melhoria, desde a simples regularidade na manutenção dos espaços
\end{abstract}




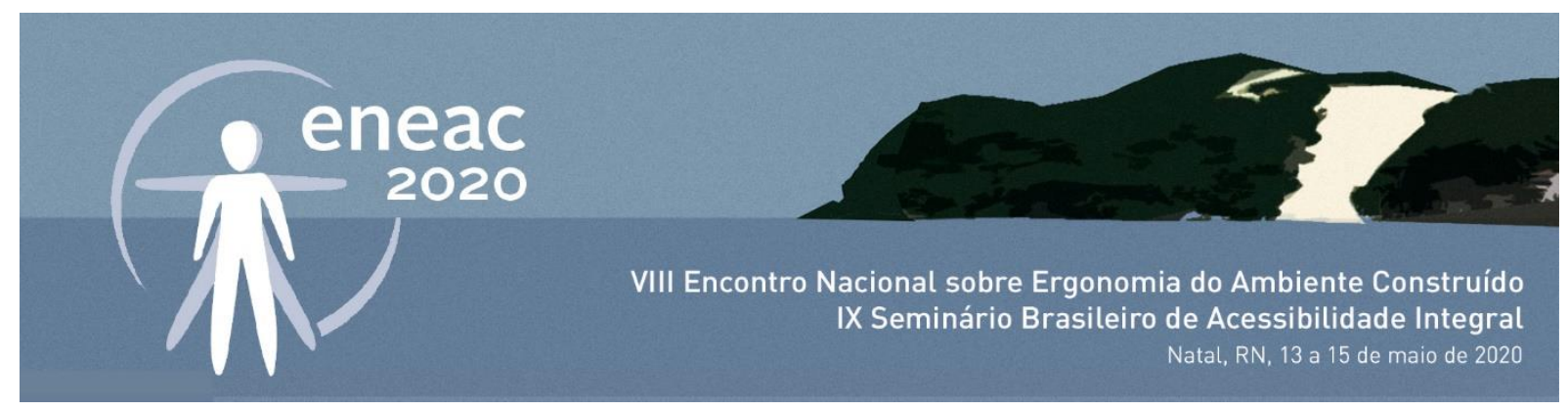

até a instalação do piso tátil na rota acessível. É importante destacar que pesquisas como essa contribuem para reforçar a necessidade dos espaços públicos, principalmente os educacionais, onde cada vez mais aumenta o número de estudantes com deficiência, de estarem aptos a promover inclusão social, ao possibilitar a livre utilização por qualquer tipo de usuário.

PALAVRAS-CHAVE: Acessibilidade; UFPE, biblioteca; rota acessível

\begin{abstract}
In Brazil, accessibility has been an issue usually perceived only from the legal point of view, but even if the country has a set of laws that in theory guarantee equal treatment for all, participate in international events on the subject and sign agreements, it has not yet developed a culture of social inclusion for people with special needs. This article has the goal to present the current conditions of accessibility of an route inside of Federal University of Pernambuco (UFPE), located in Recife - PE, more precisely in the building of the Central Library - ground floor, as well as to identify the difficulties in the mobility process of employees and students inside it. For this, an activity developed during a graduate module in "Design and Innovation in Interiors" was used as a methodology as a requirement for completion of the same, being used as a technique unsystematic observation accompanied by photographic record. The route showed that the building presents several flaws with regard to ensuring the autonomy of people with disabilities. However, such non-conformities are likely to be improved, from the simple regularity in the maintenance of spaces to the installation of the tactile floor on the accessible route. It is important to highlight that research such as this contributes to strengthening the need for public spaces, especially educational spaces, where the number of students with disabilities is increasingly increasing, being able to promote social inclusion by enabling the free use by any type of user.
\end{abstract}

KEYWORDS: Accessibility; UFPE; library; accessible route

\title{
1 INTRODUÇÃO
}

Em 2018, a fim de fornecer dados mais exatos para com a realidade do Brasil, o Instituto Brasileiro de Geografia e Estatística (IBGE) apresentou o Panorama Nacional e Internacional da Produção de Indicadores Sociais, um documento que apresenta uma variedade de dados relativos à diversos grupos sociais, dentre eles pessoas com deficiência. Utilizando a mesma base de dados do Censo de 2010 , o IBGE aponta que a proporção de pessoas com deficiência é de $6,7 \%$, bem inferior do que os $24 \%$ anteriormente apresentados. Essa queda se deve pela mudança na margem de corte aplicada pelo órgão, sendo a proposta atual o agrupamento de grupos que têm "muita dificuldade" ou "não conseguem de modo algum". Partindo da reflexão de reflexões atuais, é impossível pensar as cidades sem levar em consideração cada tipo de deficiência no momento do planejamento de políticas públicas que facilitem a vida dessas pessoas. Entretanto, os benefícios não são para todos. ${ }^{i}$

É perceptível um avanço nas políticas de inclusão atualmente. Mas, a inclusão, não se resume apenas às pessoas com alguma deficiência. Diz respeito à mãe que passeia pela calçada com um carrinho de bebê e que também deve encontrar um percurso livre de obstáculos, plano e com rampas, às calçadas largas que ajudam não só o deficiente visual, mas a pessoa obesa que pode trafegar sem 


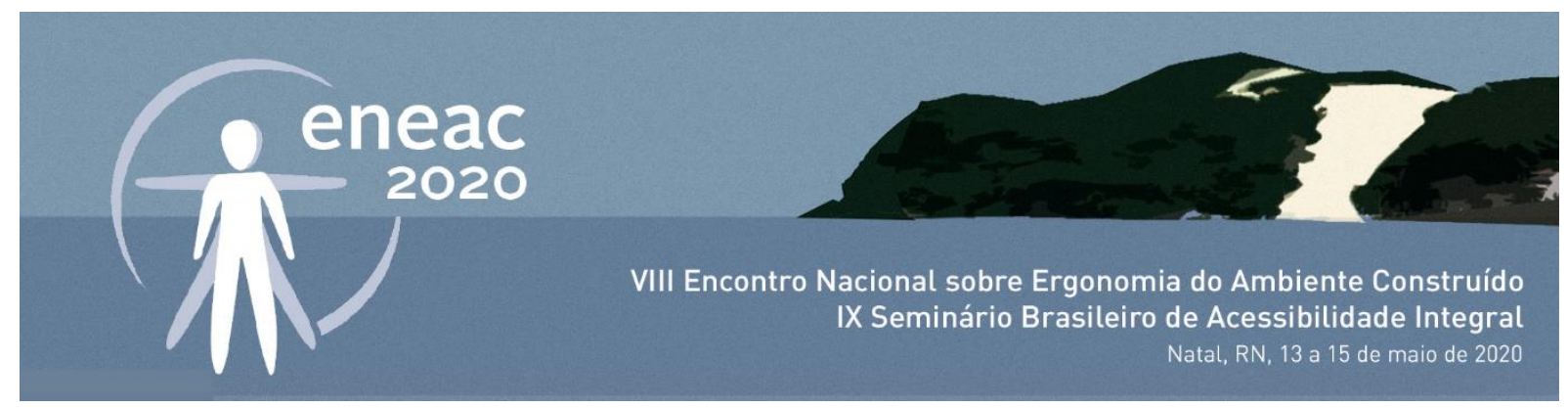

constrangimento, e permite que a pessoa idosa que utiliza algum equipamento que ajude na sua mobilidade, como andadores, trafegue com autonomia. Não só o passeio público deve ser acessível, mas o transporte público, as edificações, a informação e a própria tecnologia aplicada em cada caso. A acessibilidade é boa para todos e deve ser um exercício contínuo.

Além disso, existem os casos de limitações temporárias, em caso de lesões traumáticas, como uma fratura ou torção, que podem levar a pessoa a fazer uso de muletas ou cadeira de rodas, durante determinado período. Gestantes também não são pessoas com deficiência, mas muitas vezes podem apresentar dificuldades para se locomover em locais com escadas ou muitos desníveis e com grandes obstáculos no caminho.

Por isso, a Norma Brasileira (NBR) 9050/2015, elaborada pela Associação Brasileira de Normas Técnicas (ABNT) "estabelece critérios e parâmetros técnicos a serem observados quanto ao projeto, construção, instalação e adaptação do meio urbano e rural, e de edificações às condições de acessibilidade" (ABNT, 2015, p: 1).

Entretanto, tornar um ambiente acessível não é apenas adaptá-lo e adequá-lo às pessoas com deficiência, mas é permitir que elas, dentro das suas limitações, consigam continuar independentes, uma vez que a norma

visa proporcionar a utilização de maneira autônoma, independente e segura do ambiente, edificações, mobiliário, equipamentos urbanos e elementos à maior quantidade possível de pessoas, independentemente de idade, estatura ou limitação de mobilidade ou percepção" (ABNT, 2015, p:1).

Dessa forma, a edificação escolhida como objeto de estudo foi a Biblioteca Central da Universidade Federal de Pernambuco (UFPE), localizada na Av. Prof. Moraes Rego, 1235, no campus Recife. A escolha desse equipamento se deu pelo amplo uso das suas instalações, não apenas por alunos, professores e funcionários da universidade, mas de outras instituições e estudantes secundaristas. Além disso, a Biblioteca Central foi criada para abrigar, na maior parte dos ambientes, funções administrativas e para a realização de eventos nos auditórios, todavia, a maior parte das instalações utilizadas pelos usuários são as salas de estudo individual e coletiva.

O objetivo desta pesquisa foi analisar uma rota traçada a partir do estacionamento da biblioteca passando pelos locais de maior frequência dos usuários e pontos de interesse, como os acessos aos pavimentos superiores, do ponto de vista da organização espacial e do atendimento a norma nacional de acessibilidade, a NBR 9050/2015, visando à busca de uma rota de melhor acesso para as pessoas com restrições de mobilidade.

\section{A ACESSIBILIDADE E SUAS DIRETRIZES LEGAIS}

No Brasil, o direito de ir e vir está previsto no art. 50 da Constituição Federal de 1988, onde assegurase que todos são iguais perante a lei, sem distinção de qualquer natureza, garantindo-se aos brasileiros e aos estrangeiros residentes no País a inviolabilidade do direito à vida, à liberdade, à igualdade, à segurança e à propriedade, incluindo o direito à livre locomoção (BRASIL, 1988). Visando garantir que esta vem sendo cumprida de fato para todos, nos deparamos com a questão da acessibilidade no que diz respeito a pessoas com deficiência. 


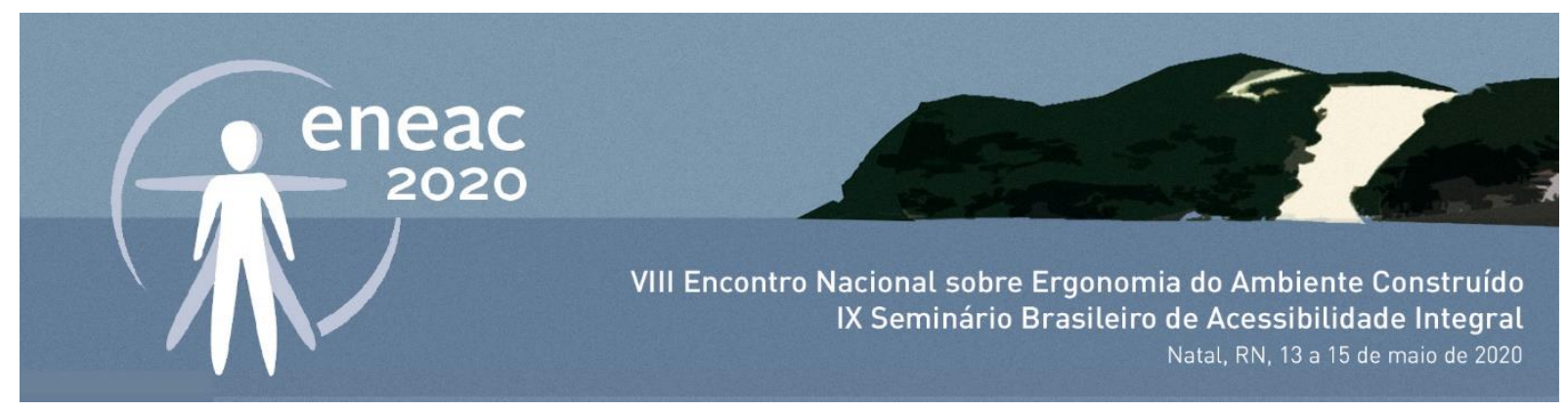

Conforme Piauí (2010), o direito à acessibilidade está visceralmente relacionado ao direito fundamental de ir e vir não só das pessoas com deficiência, mas também de direito de qualquer pessoa, independente da restrição de mobilidade, referindo-se também aos sistemas de transportes (aéreo, aquaviário e terrestre), aos equipamentos urbanos e à circulação em áreas públicas. Cabe ressaltar que a acessibilidade é um tema que vem sendo amplamente considerado em relação ao aparato legal direcionado às pessoas com deficiência. Para compreendermos melhor o assunto, fazse necessário compreendermos o termo.

A lei no 13.146, Lei Brasileira de Inclusão da Pessoa com Deficiência, define acessibilidade como a possibilidade e condição de alcance para utilização, com segurança e autonomia, de espaços, mobiliários, equipamentos urbanos, edificações, transportes, informação e comunicação, inclusive seus sistemas e tecnologias, bem como de outros serviços e instalações, abertos ao público, de uso público ou privados de uso coletivo, tanto na zona urbana como na rural, por pessoa com deficiência, ou com mobilidade reduzida (BRASIL, 2015).

De acordo com Dischinger e Bins Ely (2005), a acessibilidade é constituída por um espaço acessível que permite o usuário ir e vir, participar de todas as atividades que o local proporcione, sempre com autonomia, segurança e conforto, independente das habilidades e restrições que o indivíduo possua, dando assim escopo para que haja o pensamento crítico a respeito da materialização da acessibilidade através de uma visão mais humanitária do desenho universal, na concepção de objetos, equipamentos e estruturas destinadas na utilização dos mesmos por todos, na sua máxima extensão possível, tendo como objetivo tornar produtos, estruturas, meios de comunicação e informação e as edificações acessíveis sem necessidade de adaptação ou projeto especializado para pessoas com deficiência a baixo custo. Para tanto, temos como instrumento a NBR 9050, de 11 de novembro de 2015, mais conhecida como a norma brasileira de acessibilidade, referida acima.

No que diz respeito ao presente estudo, têm-se como foco a acessibilidade em equipamentos/instalações em instituição de ensino superior. De acordo com o decreto federal no 5.296 os "estabelecimentos de ensino de qualquer nível, etapa ou modalidades, públicos e privados, proporcionarão condições de acesso e utilização de todos os seus ambientes ou compartimentos, para pessoas com deficiência ou mobilidade reduzida", sendo a acessibilidade descrita como condição para utilização, com segurança e autonomia, total ou assistida, dos espaços, mobiliários e equipamentos urbanos, das edificações, dos serviços de transporte e dos dispositivos, sistemas e meios de comunicação e informação, por pessoa com deficiência ou com mobilidade reduzida (BRASIL, 2004).

Coulon (2008) declara que "acessar o ensino superior não garante o acesso ao saber". 0 autor descreve três tempos sucessivos para a realização da missão de tornar-se um estudante e dar continuidade a esta: "o tempo do estranhamento, o tempo da aprendizagem e o tempo da afiliação". Para o estudante que possui algum tipo de deficiência, o percurso até a afiliação apresentará dificuldades adicionais, devendo, portanto, contar com o suporte necessário para responder às demandas determinadas pela universidade.

O Brasil, em relação à educação, como política de Estado, optou pela educação inclusiva como modelo a ser implementado em território nacional, ou seja, pode-se afirmar então que a acessibilidade é, antes de tudo, um sistema de inclusão, pois compreende não somente a proposta de ambientes acessíveis como também é excepcionalmente abrangente no que diz respeito aos indivíduos contemplados no conceito. 


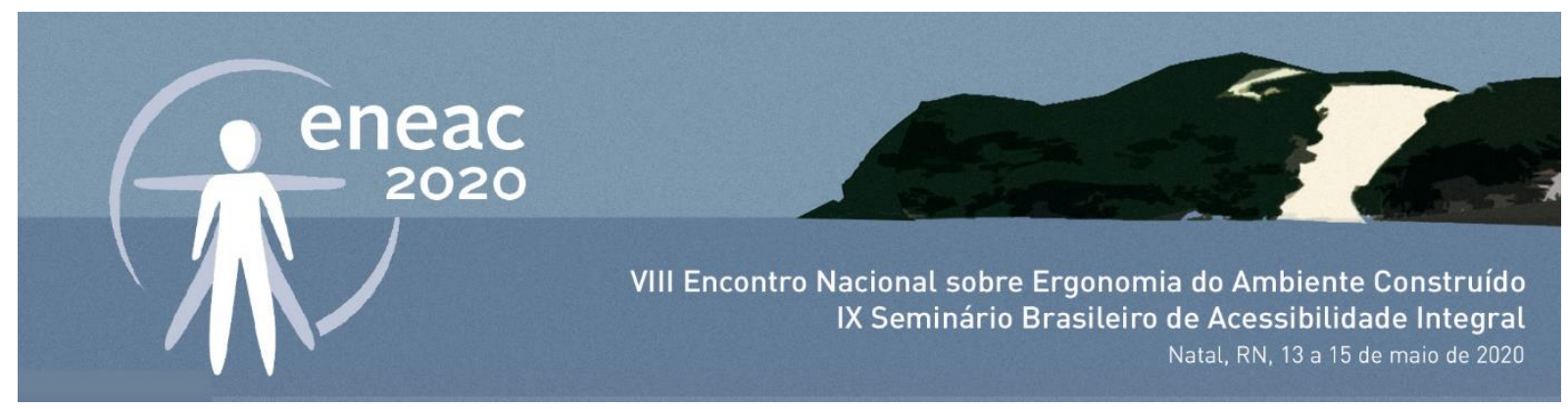

\section{ASPECTOS PRÁTICOS}

O ingresso de estudantes com Necessidades Educacionais Especiais - NEE, especificamente daqueles com deficiência nas universidades não é mais uma utopia, mas a acessibilidade no Brasil é um processo em desenvolvimento, pois sua efetivação pressupõe não somente de uma legislação progressista como também uma sociedade disposta a eliminar barreiras e gestores com empenho político para facilitar esse processo. De forma mais específica, no gráfico 1 a seguir podemos visualizar o número de matrículas em cursos de graduação de alunos por tipo de deficiência no ano de 2017:

Gráfico 1: Número de Matrículas em Cursos de Graduação de Alunos com Deficiência, Transtornos Globais do Desenvolvimento ou Altas Habilidades/Superdotação, por Tipo de Deficiência - 2017.

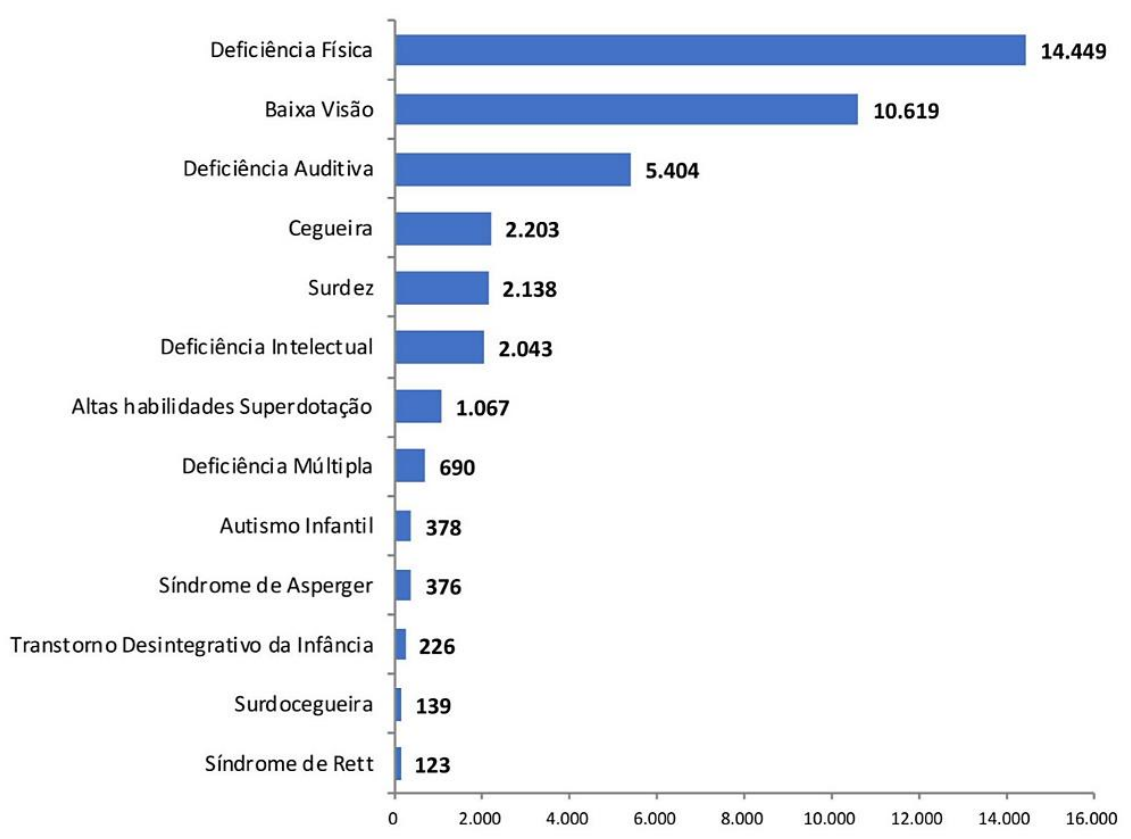

Fonte: MEC/INEP, 2017.

De acordo com a imagem acima (gráfico 1), a grande maioria dos estudantes com deficiência que ingressam no ensino superior, possuem limitação física ou mobilidade reduzida permanente ou transitória. Com isso, mostra-se a relevância de observar as normas e legislações vigentes no que concerne à concepção de espaços para que estes possam desenvolver seus conhecimentos sem maiores dificuldades do que Ihes já são impostas pela natureza de sua condição, repensando da política institucional com vistas a implementar mudanças efetivas que garantam a esses estudantes os recursos necessários para que possam desempenhar as atividades inerentes ao ensino superior ao longo de sua trajetória acadêmica.

As ações afirmativas estão sendo implementadas em grande parte das instituições de ensino superior, porém ainda são escassos os estudos analisando a situação dos estudantes com deficiência diante dessas políticas (DUARTE et al, 2013). As ações afirmativas surgem com o intuito de pôr em prática a inclusão social da parcela discriminada pela sociedade, estas podem ser realizadas tanto 


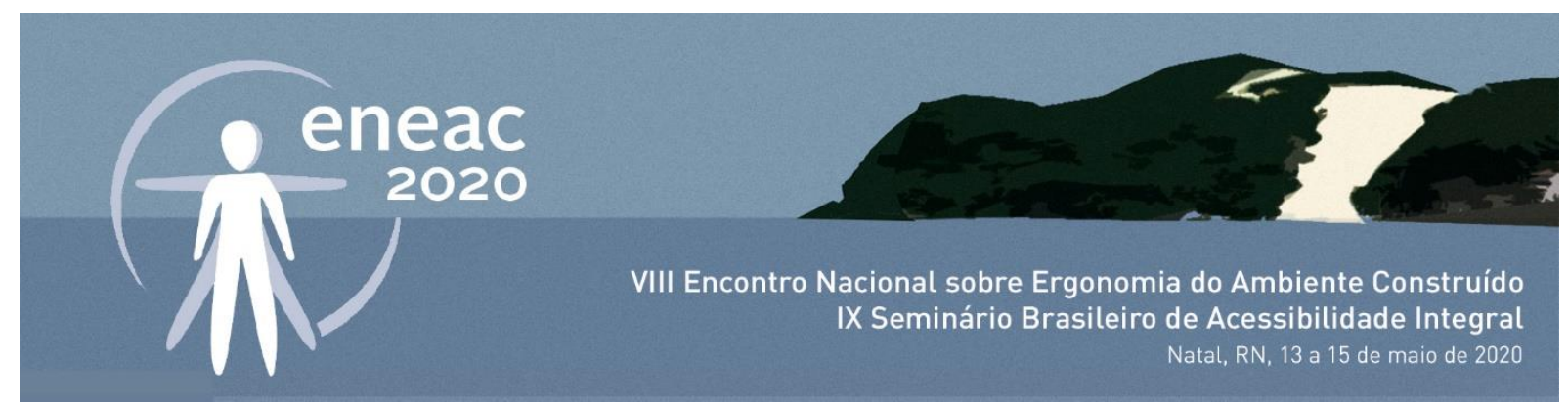

pelo poder público quanto pela sociedade. Neste contexto, as ações afirmativas constituem-se como um meio para promover a igualdade de oportunidade a todos.

A Portaria no 3.284, de 7 de novembro de 2003 condiciona o credenciamento de novos cursos e instituições de ensino superior à proposição de ambientes acessíveis, possibilitando o acesso à Educação Superior por pessoas com deficiência, uma vez que as universidades, em consonância com o Estado, têm praticado algumas políticas de inclusão educacionais favorecendo o acesso e a permanência desses grupos, visando a materialização da acessibilidade (BRASIL, 2003).

\section{ACESSIBILIDADE E A UFPE}

\subsection{Programa INCLUIR - acessibilidade na educação superior}

De acordo com o Documento Orientador - Programa INCLUIR, a discussão das políticas educacionais fortalece a necessidade de composição e implementação de ações voltadas para o acesso aos ambientes de ensino. A proposta de um sistema educacional inclusivo passa a ser percebida como processo de reflexão e prática, que possibilita efetivar mudanças conceituais, político e pedagógicas, coerente com o propósito de tornar efetivo o direito de todos à educação (BRASIL, 2013).

No mesmo documento, afirma-se que a partir da adoção de políticas públicas que objetivam a inclusão social, foi criado em 2005, o "Programa INCLUIR - acessibilidade na educação superior", executado por meio de parceria entre a Secretaria de Educação Superior - SESU e a Secretaria de Educação Continuada, Alfabetização, Diversidade e Inclusão - SECADI, sendo implementado até 2011, onde as instituições federais de ensino superior (IFES) apresentaram projetos de criação e consolidação dos Núcleos de Acessibilidade, garantindo a inclusão de pessoas com deficiência à vida acadêmica, visando eliminar barreiras físicas, pedagógicas, nas comunicações e informações, nos ambientes, instalações, equipamentos e materiais didáticos, promovendo o cumprimento dos requisitos legais de acessibilidade. A partir de 2012, esta ação foi universalizada atendendo todas as IFES, induzindo, assim, o desenvolvimento de uma Política de Acessibilidade ampla e articulada.

\subsection{NACE UFPE}

Com finalidade de institucionalizar as ações políticas de acessibilidade na educação superior, em junho de 2014 nasceu o Núcleo de Acessibilidade da Universidade Federal de Pernambuco (NACE/UFPE).

De acordo com o Núcleo de Acessibilidade da UFPE, o mesmo tem como objetivos:

- Promover a inclusão, a permanência e o acompanhamento de pessoas com deficiência e necessidades específicas, nos diversos níveis de ensino oferecidos por esta instituição, garantindo condições de acessibilidade na UFPE;

- Articular-se intersetorialmente frente às diferentes ações já executadas na UFPE, assim como na promoção de novas ações voltadas às questões de acessibilidade e inclusão educacional, nos eixos da infraestrutura; comunicação e informação; ensino, pesquisa e extensão;

- Oferecer Atendimento Educacional Especializado (AEE), a partir de uma equipe multidisciplinar, voltado para seu público-alvo; 


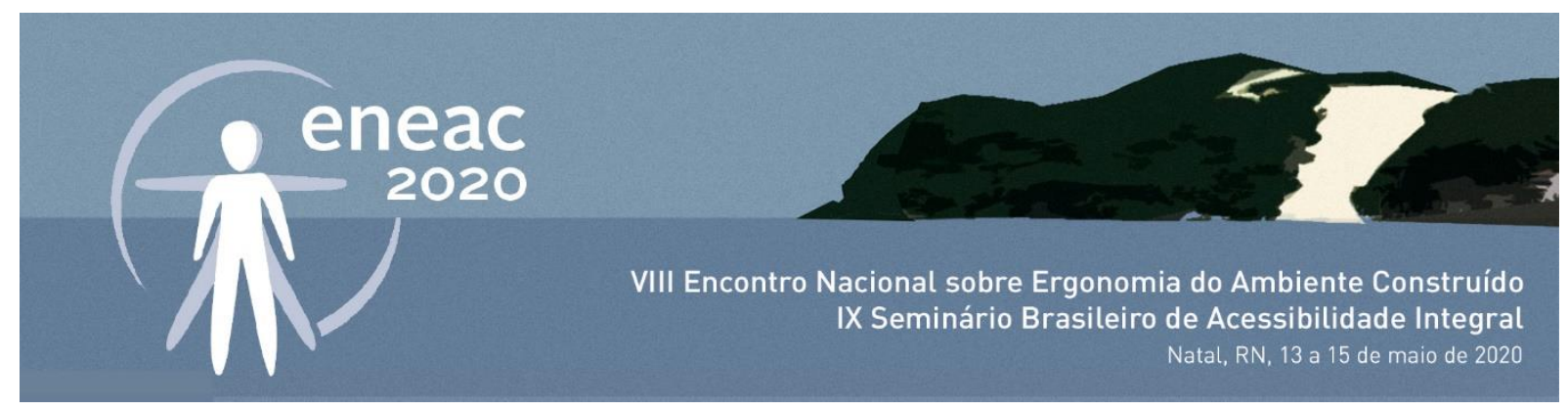

Entre as iniciativas realizadas pelo NACE em prol da inclusão dos alunos PcD (Pessoa com Deficiência) estão a produção de materiais acessíveis em braile, acompanhamento de alunos com necessidades específicas, orientações pedagógicas para docentes e técnicos para o atendimento de discentes com necessidades específicas, empréstimos de tecnologias assistivas, como cadeiras de rodas, scanner de voz e lupa eletrônica, e tradução/ interpretação para Libras de palestras, aulas, eventos e demais atividades de ensino, pesquisa e extensão.

\section{BIBLIOTECA CENTRAL UFPE E A ROTA ACESSÍVEL}

O presente estudo foi realizado a partir de pesquisa realizada na Biblioteca Central da Universidade Federal de Pernambuco (UFPE), localizada na Av. Prof. Moraes Rego, 1235, no campus Recife (figura 1). A principal referência temporal de criação da Universidade Federal de Pernambuco é a data de 11 de agosto de 1946, dia da fundação da Universidade do Recife (UR). Os dados para a realização deste trabalho foram adquiridos na Prefeitura da Universidade Federal de Pernambuco, uma base cartográfica cuja última atualização ocorreu em 2018, e durante as visitas realizadas, fotografias e realização de medições de vãos, portas e etc.

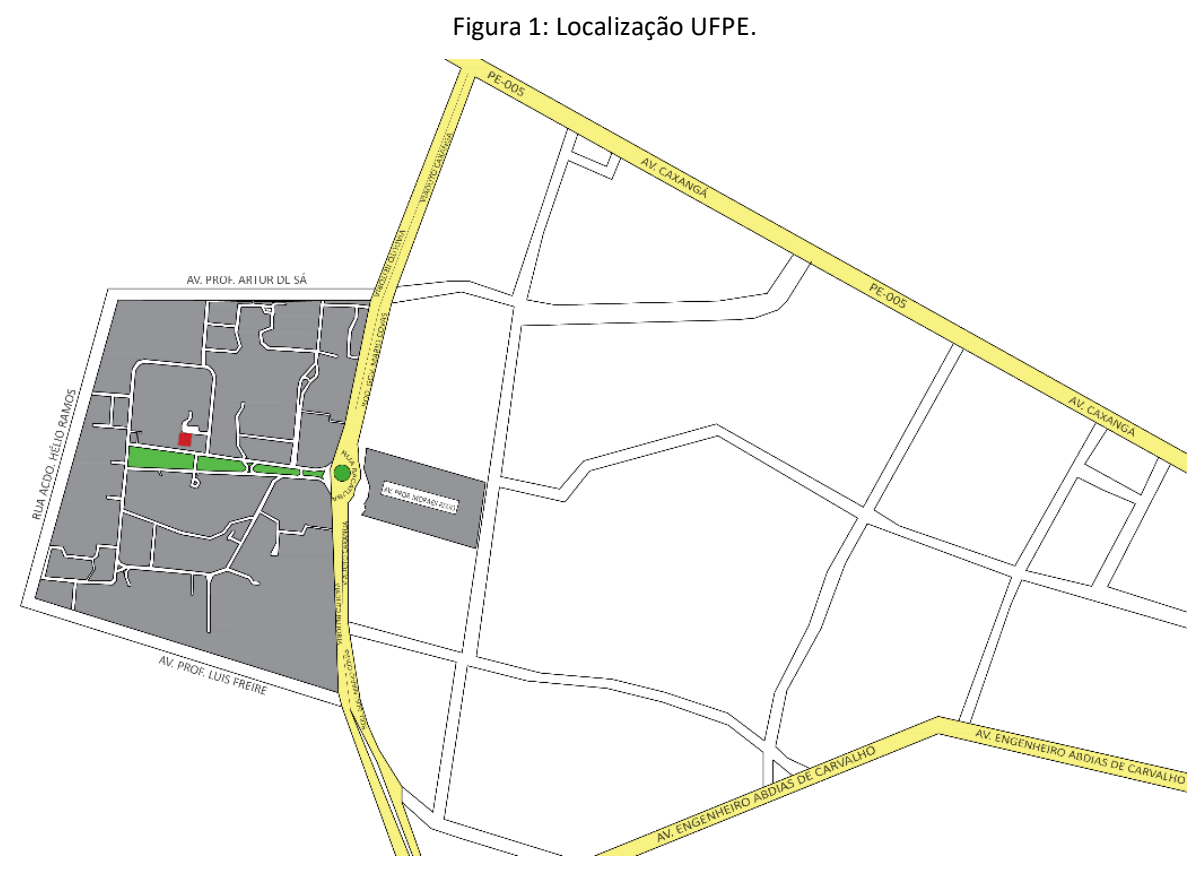

Fonte: Prefeitura da UFPE, edição dos autores (2020).

A construção do campus do Recife começou em 1948, e em 1953, instituiu-se na Universidade do Recife a Biblioteca Central (figura 2). 

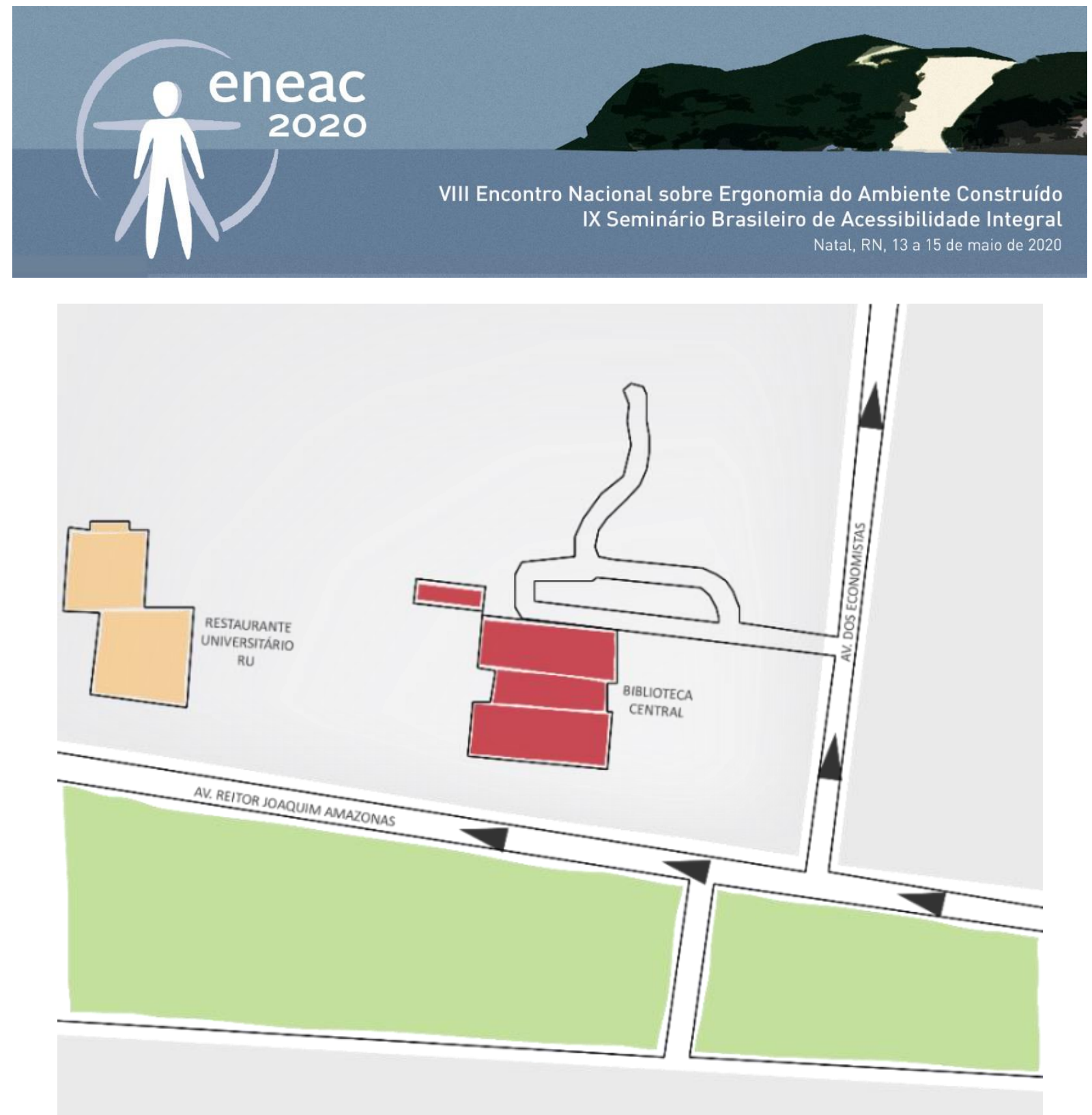

Fonte: Prefeitura da UFPE, edição dos autores (2020).

O procedimento metodológico utilizado foi o desenvolvimento de uma atividade na pós-graduação em "Design de Interiores e Inovações" no módulo de "Design Universal e Cognição do Espaço", ministrada pelo professor Júlio Fernandes, no Centro Universitário UNIESP, localizado na cidade de João Pessoa, estado da Paraíba. Para a atividade, foi realizada uma análise de possível rota acessívelii em determinado local de uso público, conforme imagem abaixo, com o resultado da avaliação (figura 3). A análise foi realizada no mês de dezembro de 2019 , e utilizou como principais técnicas a observação assistemática acompanhada do registro fotográfico de todas as etapas. 


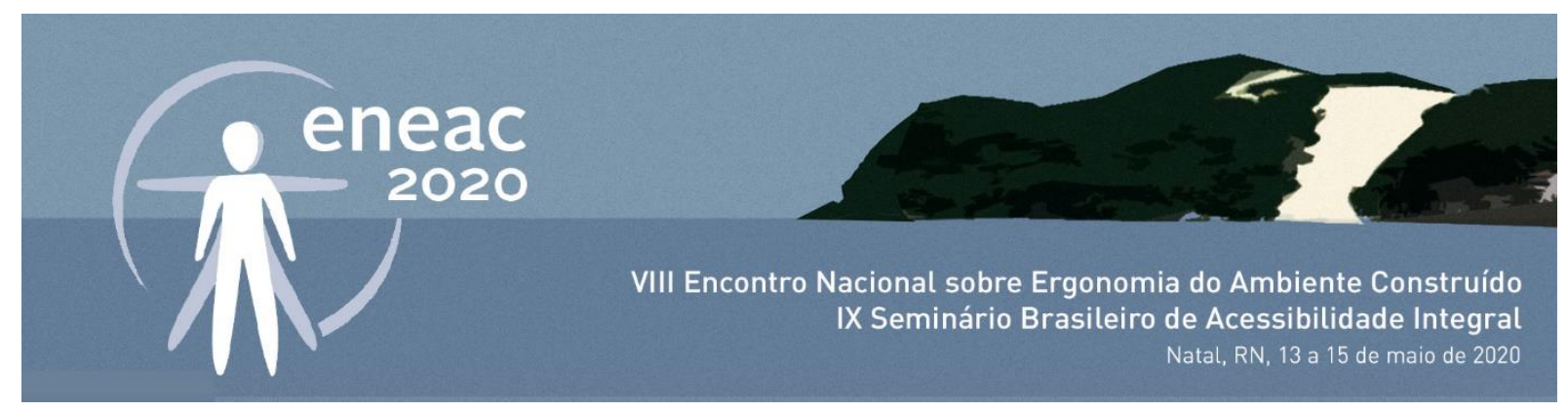

Figura 3: Material produzido durante a disciplina.

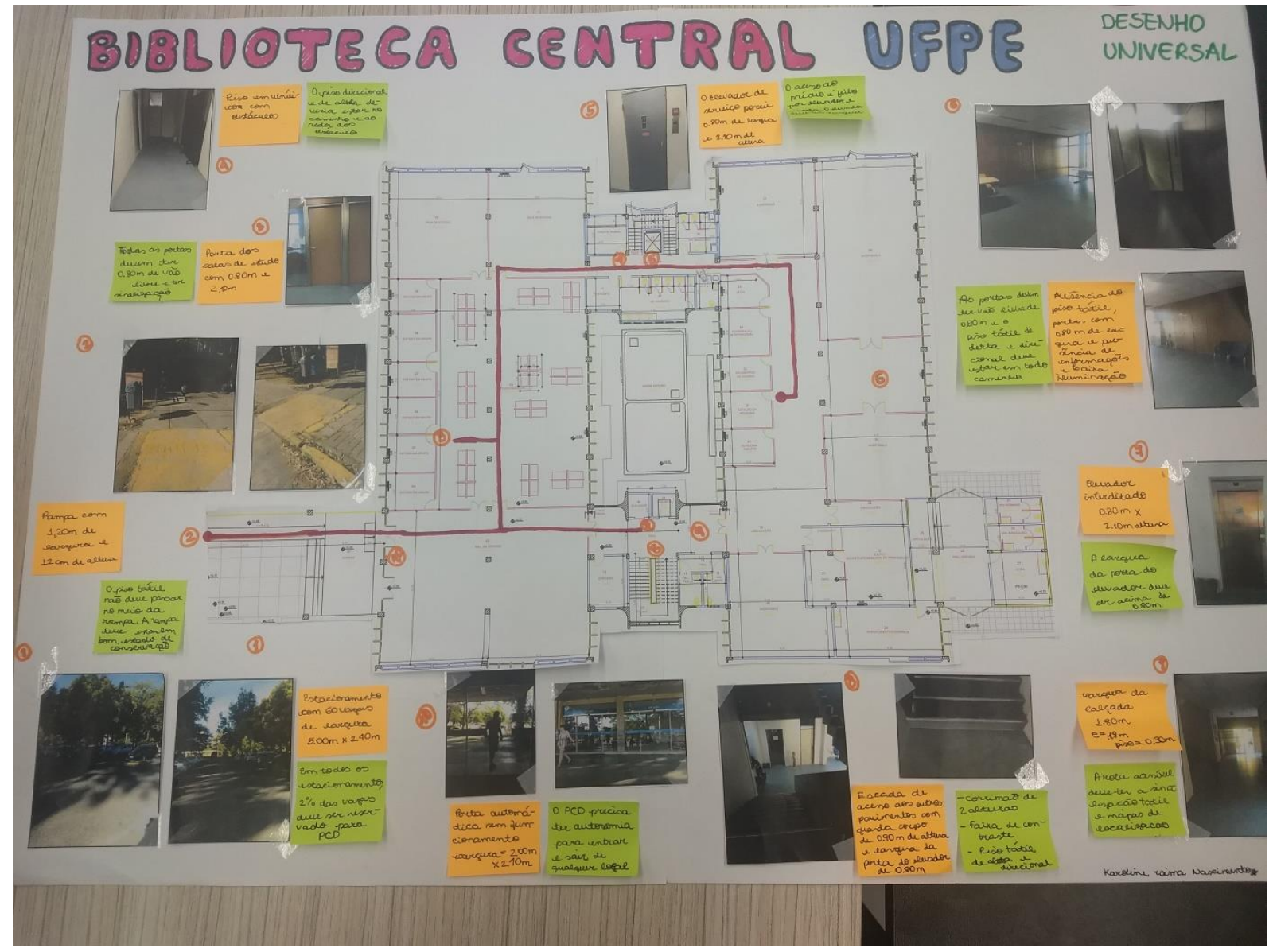

Fonte: Prefeitura da UFPE, edição dos autores (2019).

O levantamento físico foi realizado a partir do estacionamento até o pavimento térreo da edificação, com o auxílio de uma fita métrica, bem como registros fotográficos, para que estes pudessem corroborar visualmente o comparativo com os parâmetros estabelecidos na NBR 9050 (ABNT, 2015). $O$ estudo deteve-se à análise do seguinte trajeto: a partir do estacionamento (1), que leva a calçada de acesso (2), direcionando para porta de entrada principal da Biblioteca Central, passando pelo hall de entrada. Se seguirmos em frente, nos depararemos com o primeiro elevador da edificação (7) e em frente deste, as escadas de acesso (8). Se voltarmos para o hall de entrada e virarmos à esquerda, temos a passagem pela área de estudo individual e anexas às estas estão as salas de estudo em grupo (3). Ao seguir o trajeto definido para o estudo, chegamos ao elevador (5) e mais à frente, ao fim do trajeto, chegamos à estação de pesquisa, como podemos observar na imagem a seguir (figura 4). 


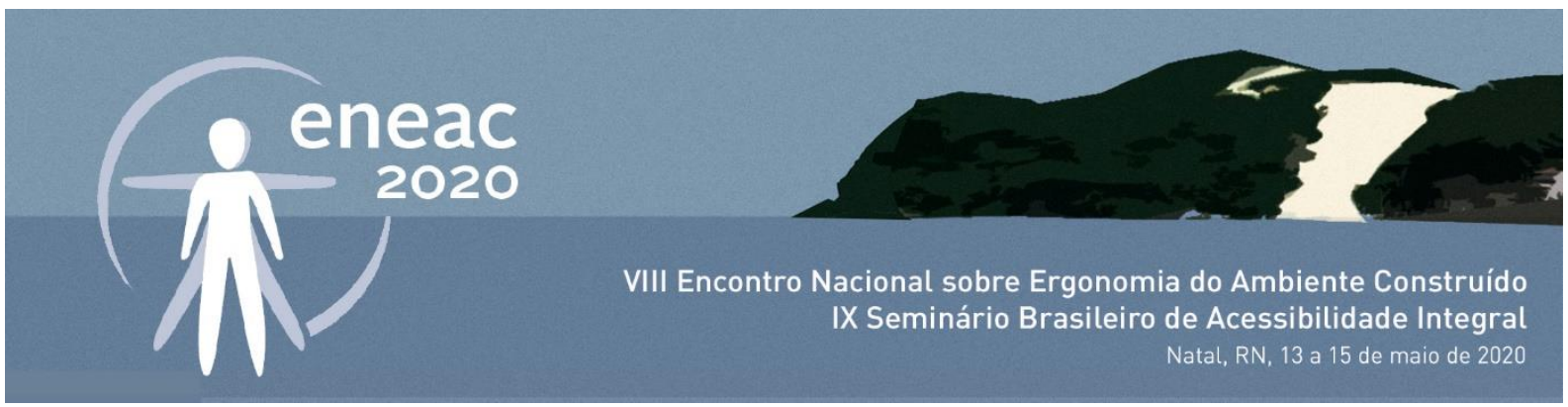

Figura 4: Biblioteca Central UFPE - Térreo Pavimento /Rota Analisada.

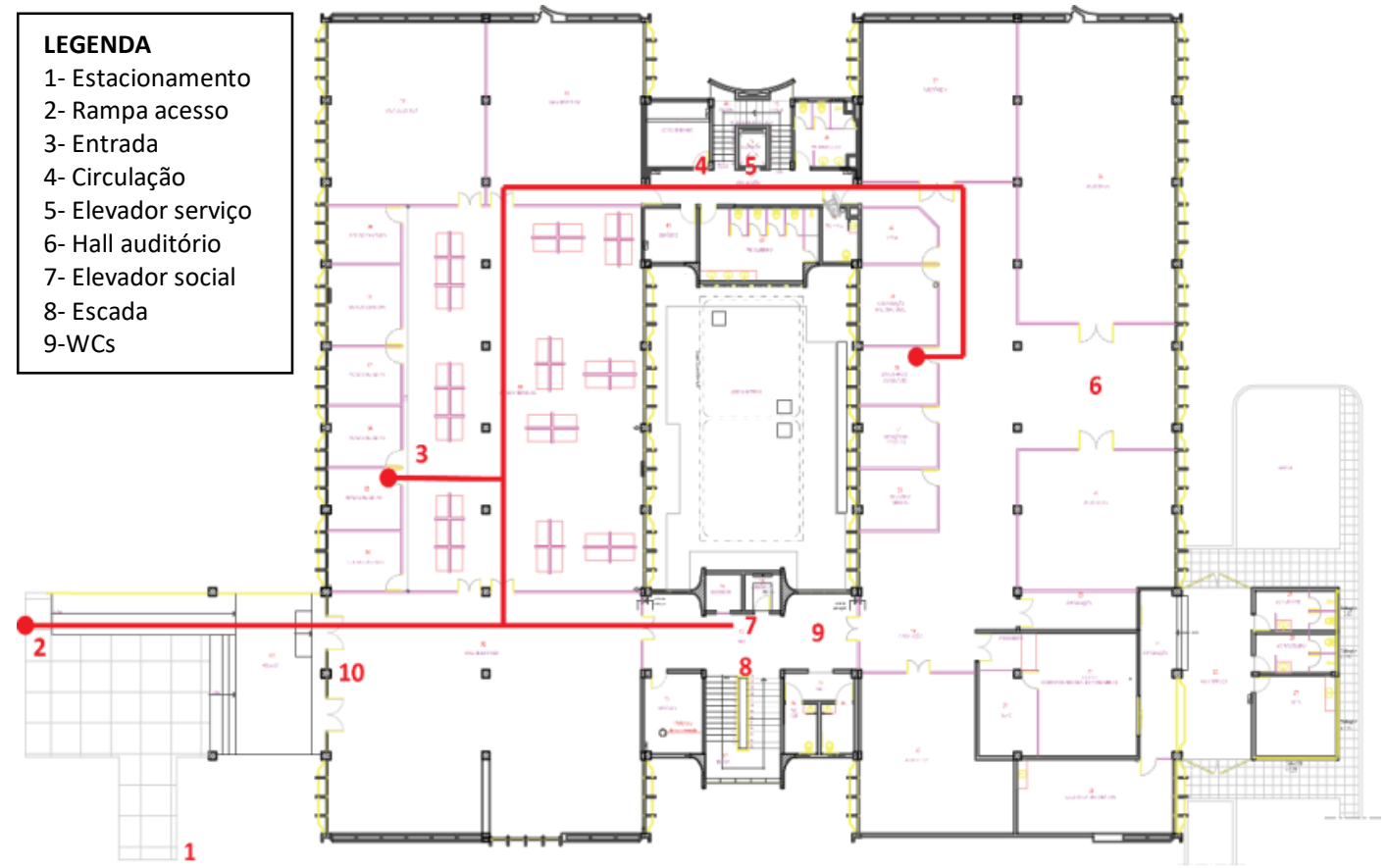

Fonte: Prefeitura da UFPE, edição dos autores (2020).

Existem pontos críticos na acessibilidade do local que aqui serão analisados em consonância com a NBR 9050 (ABNT, 2015). O primeiro deles foi observado no estacionamento (ponto 1- figura 5), onde não existe a sinalização das vagas reservadas a idosos e para as pessoas em cadeiras de roda (P.C.R.), conforme visto na figura 5 e 6 . A norma assegura que em locais de atendimento público, deve existir pelo menos um espaço destinado para pessoa em cadeira de rodas - P.C.R. Além disso, "nas edificações e equipamentos urbanos, todas as entradas, bem como as rotas de interligação às funções do edifício, devem ser acessíveis" (ABNT, 2015, p: 54), mas que só garante a livre utilização dos usuários caso seja vinculado através de rota acessível aos acessos principais e de emergência, o que também não ocorre, a começar pelo tipo de piso do estacionamento que causa trepidações no deslocamento de dispositivos com rodas e não possui piso tátil direcional.

Figura 5 e 6: Estacionamento da Biblioteca Central UFPE.
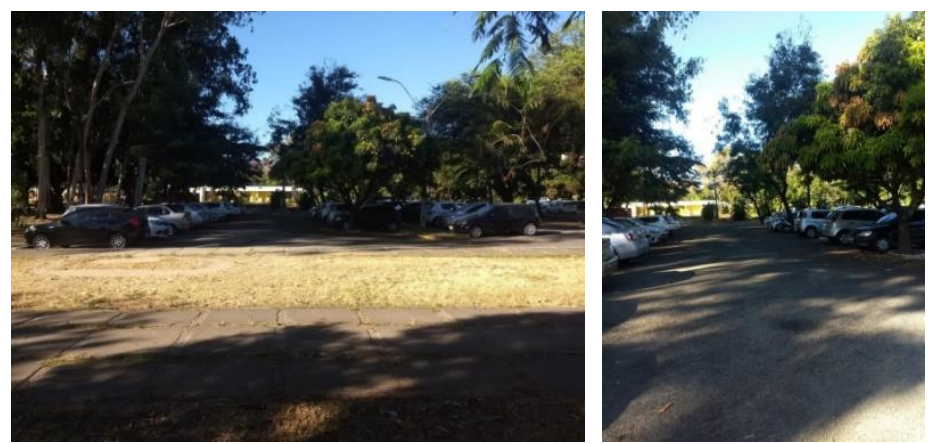

Fonte: Acervo pessoal dos autores (2019). 


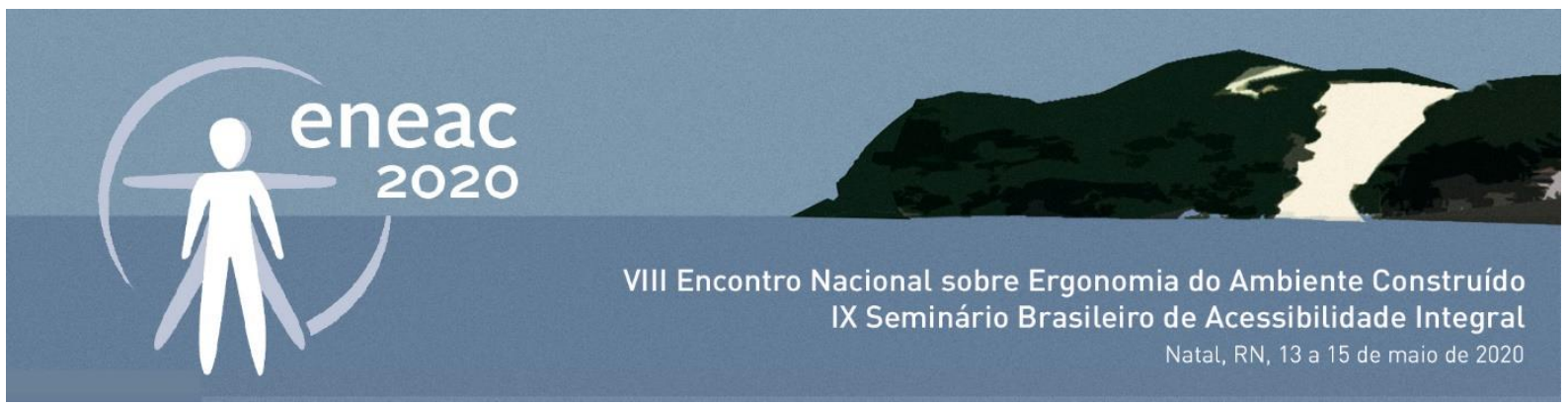

Mesmo após a reforma realizada em todas as calçadas do campus no ano de 2018, elas ainda oferecem dificuldades pela falta de manutenção e conservação, como a guia rebaixada de acesso à calçada, segundo ponto da rota, que, embora atenda as especificações de dimensões da norma, está desgastada, além de ter o piso tátil passando pelo centro da guia rebaixada (figura 7 e 8). Foi importante observar esse trecho, pois "a rota acessível externa incorpora estacionamentos, calçadas, faixas de travessias de pedestres (elevadas ou não), rampas, escadas, passarelas e outros elementos da circulação" (ABNT, 2015, p: 54), não apenas as instalações internas da edificação.

Figura 7 e 8: Rampas de acesso à entrada da biblioteca.
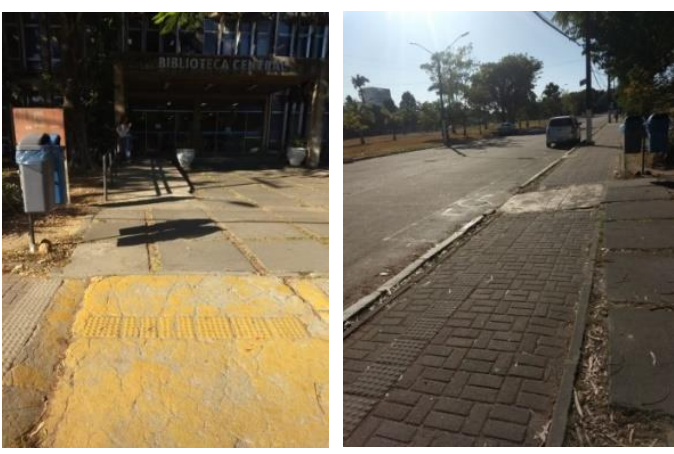

Fonte: Acervo pessoal dos autores (2019).

No ponto 3, temos o acesso as salas de estudo individuais, que possuem vão mínimo de 0,80 $\mathrm{m}$ de largura e altura de $2,10 \mathrm{~m}$, conforme especificado em norma. As maçanetas das portas são do tipo alavanca e permitem a abertura com um único movimento. Entretanto, no ponto 5 nos deparamos com um elevador que foi instalado para ser de uso comum, mas que é utilizado apenas pelos funcionários responsáveis pela limpeza, sendo definido como o elevador de serviço.

O ponto 6 (figura 9 e 10) é um dos pontos mais críticos. No hall existente entre os auditórios os maiores problemas foram a ausência de assentos especiais e demarcados, ausência do piso tátil em toda a rota, além da inexistência de informações em braile para deficientes visuais e de o piso ser de uma única cor, como pontuado no ponto 4, referente a circulação que dá acesso ao ponto 6 também. O contraste entre as cores e texturas das superfícies é necessário por ser útil ao usuário que possui baixa visão, sendo a sinalização tátil a maneira mais eficiente de para que os obstáculos sejam identificados, garantindo autonomia e segurança na locomoção.

Figura 9 e 10: Hall de acesso aos auditórios do piso térreo. Eles também funcionam como local de estudo quando as mesas das salas de estudos estão lotadas.
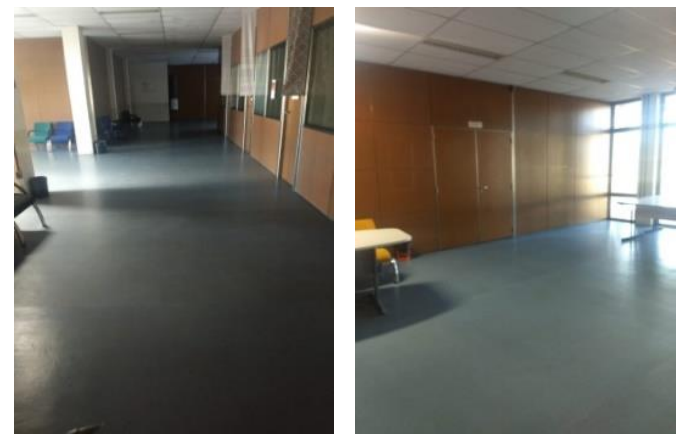

Fonte: Acervo pessoal dos autores (2019) 


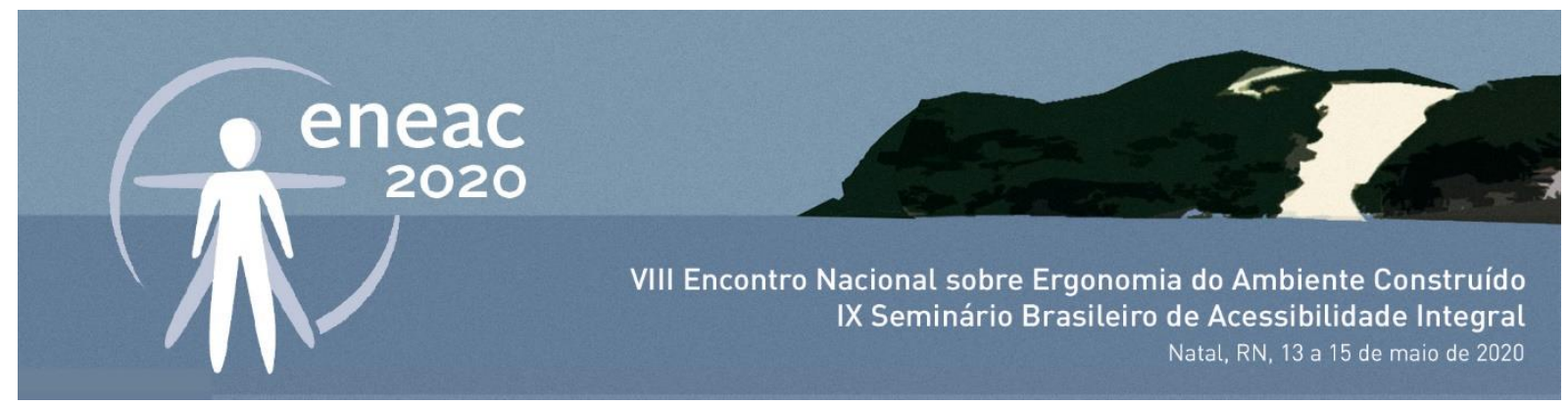

O ponto 7 e 8 refere-se a dois conflitos sem solução até a realização da pesquisa: o elevador utilizado pelos usuários está interditado há meses, restando apenas o acesso aos pisos superiores por meio da escada. Dessa forma, o acesso aos pavimentos superiores por uma P.C.R. fica totalmente comprometido, bem como a um deficiente visual, que não encontra nenhuma sinalização ao tentar utilizar a escada (figura 11 e 12).

Figura 11 e 12: Elevador e escada de acesso aos pavimentos superiores.
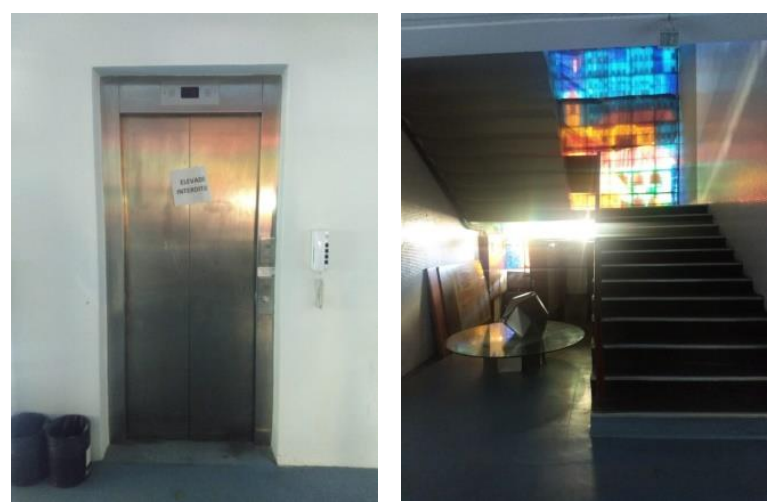

Fonte: Acervo pessoal dos autores (2019)

Embora atenda as especificações de dimensões, como largura mínima de 1,20 m, a escada não possui corrimão em duas alturas e nem faixa de contraste nos degraus ou piso tátil de alerta no começo e fim da mesma. O ponto 9 refere-se ao acesso aos banheiros, que possui vão mínimo dentro da norma, além de ambos serem acessíveis.

Por fim, tem-se o ponto 10, que se refere ao acesso principal a edificação: as portas automáticas estão quebradas há meses e, atualmente a entrada e saída da biblioteca é feita de forma manual, empurrando-se as folhas de correr. Entretanto, como a porta não foi feita para tal finalidade, a mesma oferece resistência sempre que se tenta abri-la ou fechá-la o que dificulta o processo de entrada e saída dos usuários, seja P.C.R. ou não (figura 13).

Figura 13: A porta de entrada principal da Biblioteca Central da UFPE.

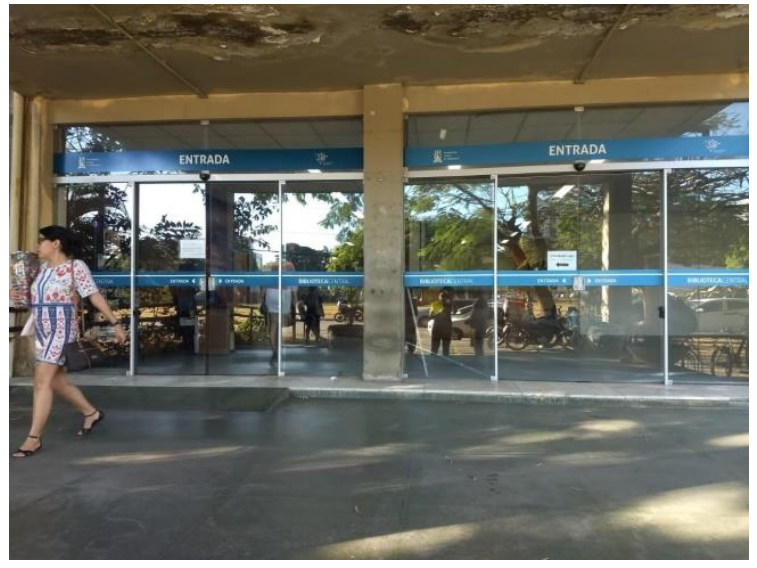

Fonte: Acervo pessoal dos autores (2019). 


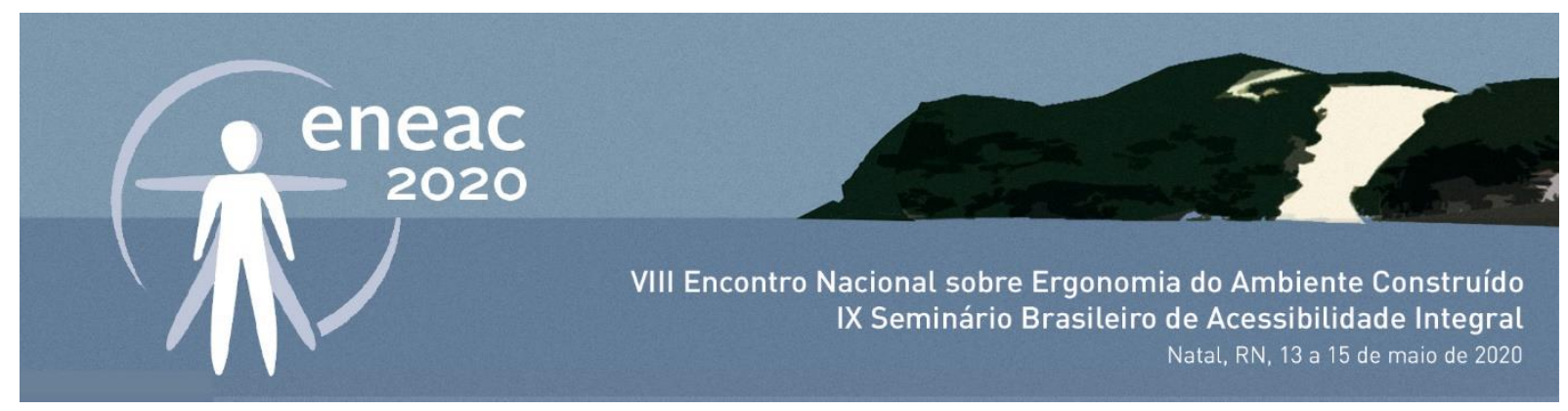

É importante destacar que o NACE está localizado no segundo andar do prédio da Biblioteca, entretanto, fica evidente que é muito difícil que uma P.C.R., com deficiência visual, ou até mesmo um idoso, chegue com total autonomia às instalações do núcleo.

\section{CONCLUSÃO}

Constata-se a facilidade visual de avaliar as potencialidades e as deficiências quanto às condições de acessibilidade da Biblioteca Central da UFPE. A pesquisa evidenciou que há um atendimento parcial em relação às normas de acessibilidade, considerando que o equipamento falha por não garantir a autonomia dos usuários com deficiência dentro da edificação e também em seu entorno. A quantidade maior de falhas na edificação é relacionada à acessibilidade para as pessoas com deficiência visual, pois a maior parte da edificação não possui piso tátil, qualquer sinalização em braile ou mapa tátil.

Entretanto, sobre as condições não conformes de acessibilidade detectadas ao longo da rota acessível definida, pode-se considerar que grande parte das dificuldades encontradas é passível de ser amenizadas a partir da adoção da manutenção das instalações de forma constante. A criação de áreas de estacionamentos que atendam ao especificado em norma e a ampliação e preservação das rampas de acesso entre os estacionamentos e o devido prédio, também seria uma das principais medidas de melhoria. Além da instalação do piso tátil direcional e principalmente, de alerta e de mapas táteis que permitam que o deficiente visual se localize dentro dos ambientes da edificação.

Sendo o maior público dentre as pessoas com deficiência no ensino superior, os estudantes cadeirantes são os principais afetados por problemas que não deveriam acontecer, como o da manutenção dos elevadores e das rampas de acesso à edificação, uma vez que a universidade deve priorizar a resolução ou minimização dessas dificuldades que afetam diretamente a mobilidade desses usuários.

É importante levar em consideração que um ambiente público desse tipo deve estar adaptado para garantir o livre acesso de todos os usuários, pois "a acessibilidade é um fator que requer um planejamento e um constante gerenciamento, pois atua sobre o direito fundamental de ir e vir além de promover uma inclusão social para todas as pessoas sejam elas com ou sem deficiência" (FONSECA et al, 2016, p:1).

\section{REFERÊNCIAS}

ALVES, G. C. Políticas públicas para pessoas com deficiência: aparato legal e implementação no ensino superior / Gilmara Cardoso Alves. - 2016.

ASSOCIAÇÃO BRASILEIRA DE NORMAS TÉCNICAS. NBR 9050: Acessibilidade a edificações, mobiliário, espaço e equipamentos urbanos. 3 ed. Rio de Janeiro: ABNT, 2015. 148 p. Disponível em: < http://www.turismo.gov.br/sites/default/turismo/o_ministerio/publicacoes/downloads_publicacoes/NBR9050.pdf>. Acesso em: 26 jan. 2020.

BRASIL. Constituição (1988). Constituição da República Federativa do Brasil. Brasília, DF: Senado Federal: Centro Gráfico, 1988. 


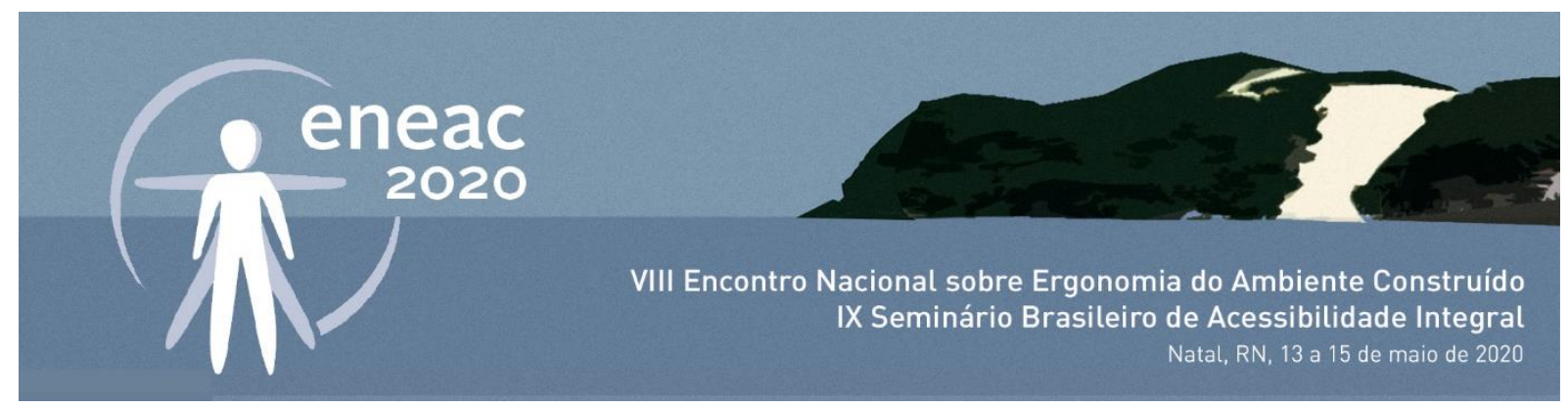

BRASIL. Decreto no 5.296 de 2 de dezembro de 2004. Regulamenta as Leis nos 10.048, de 8 de novembro de 2000, e 10.098, de 19 de dezembro de 2000.

BRASIL. Lei no 13.146, de 06 de julho de 2015. Lei Brasileira de Inclusão da Pessoa Com Deficiência: Estatuto da Pessoa com Deficiência. Disponível em: <http://www.planalto.gov.br/ccivil_03/_ato2015-2018/2015/lei/l13146.htm>. Acesso em: 26 jan. 2020.

BRASIL. MEC. 2017. Disponível em: < http://portal.mec.gov.br/docman/setembro-2018-pdf/97041-apresentac-a-o-censosuperior-u-ltimo/file>. Acesso em: 26 jan. 2020.

BRASIL. Portaria no 3.284, de 7 de novembro de 2003. Dispõe sobre requisitos de acessibilidade de pessoas portadoras de deficiências, para instruir os processos de autorização e de reconhecimento de cursos, e de credenciamento de instituições. Diário Oficial da República Federativa do Brasil, Brasília, DF, 3 dez. 1999. Disponível em: < http://portal.mec.gov.br/sesu/arquivos/pdf/c1_1679.pdf >. Acesso em: 26 jan. 2020.

BRASIL. Ministério da Educação. Documento orientador: Programa Incluir-Acessibilidade na Educação Superior. Brasília, 2013. Disponível em: < http://portal.mec.gov.br/index.php?option=com_docman\&view=download\&alias=13292-doc-oriprogincl\&category_slug=junho-2013-pdf\&Itemid=30192 >. Disponível em: Acesso em: 26 jan. 2020.

COULON, A. A condição de estudante: a entrada na vida universitária. 1. ed. Salvador: Edufba, 2008;

DESAFIO de uma época. UFPE, 2020. Disponível em: < https://www.ufpe.br/institucional/historia>. Acesso em: 26 jan. 2020.

DINIZ, D. O que é deficiência. São Paulo: Brasiliense, 2007.

DISCHINGER, M.; BINS ELY, V.H. M. Promovendo acessibilidade nos edifícios públicos: Guia de avaliação e implementação de normas técnicas. Santa Catarina: Ministério Público do Estado, 2005.

DUARTE, E.R.; RAFAEL, C.B.S.; FILGUEIRAS, J.F.; NEVES, C.M.; FERREIRA, M.E.C. (2013). Estudo de Caso Sobre a Inclusão de Alunos com Deficiência no Ensino Superior. Revista Brasileira de Educação Especial, 19 (2), 289-300.

ESTADÃO. Com nova margem de corte, IBGE constata $6,7 \%$ de pessoas com deficiência no Brasil. Disponível em: $<$ https://educacao.estadao.com.br/blogs/educacao-e-etc/com-nova-margem-de-corte-ibge-constata-67-de-pessoas-comdeficiencia-no-brasil/>. Acesso em: 30 jan. 2020.

FONSECA, R. C. D. F.; SOUZA JÚNIOR, F. L. D.; SIQUEIRA, E. D. S.; X, A.; SATO, S. S. Avaliação da acessibilidade dos estacionamentos do campus da universidade federal de Pernambuco. In: Anais do VI Simpósio Brasileiro de Ciências Geodésicas e Tecnologia da Geoinformação - UFPE - Recife, 2016.

INSTITUTO BRASILEIRO DE GEOGRAFIA E ESTATÍSTICA. Censo Demográfico 2010. Disponível em: <http://www.ibge.gov.br>. Acesso em: 14 nov. 2015.

PIAUÍ. Gardênia Lúcia Val de Melo. Secretaria Estadual para a Inclusão de Pessoa Com Deficiência. A cidade para todos: O direito à acessibilidade das pessoas com deficiência. 2. ed. Teresina, 2010. 48 p.

ROSSATTO, L. Como as pessoas com deficiência podem melhorar as cidades. <Disponível em: http://outracidade.uol.com.br/como-as-pessoas-com-deficiencia-podem-melhorar-as-cidades/>. Acesso em: 08 março 2018.

SISTEMA Integrado de Bibliotecas. UFPE, 2020. Disponível em: < https://www.ufpe.br/sib/sobre>. Acesso em: 26 jan. 2020. SOBRE o Nace. UFPE, 2020. Disponível em: <https://www.ufpe.br/nucleodeacessibilidade/sobre>. Acesso em: 26 jan. 2020.

\section{NOTAS}

i ROSSATTO (24/09/2015).

ii Rota Acessível: Trajeto contínuo, desobstruído e sinalizado, que conecta os ambientes externos ou internos de espaços e edificações, e que possa ser utilizado de forma autônoma e seguro por todas as pessoas, inclusive aquelas com deficiência. A rota acessível externa pode incorporar estacionamentos, calçadas rebaixadas, faixas de travessia de pedestres, rampas, etc. A rota acessível interna pode incorporar corredores, pisos, rampas, escadas, elevadores etc. 